\title{
Complications of Cataract Surgery at the University Teaching Hospital, Benin City, Nigeria
}

\author{
CU Ukponmwan, MBBS, FMCOphth, FWACS, EU Ogborogu, MBBS, W Ovienria, MBвS
}

University of Benin Teaching Hospital, Benin City, Nigeria

SUMMARY

Objective: To find out the complications of cataract extraction and their effect on visual outcome at the University Teaching Hospital, Benin City, Nigeria

Materials and methods: Three hundred and seventy eyes (370) that had cataract extraction at University of Benin Teaching Hospital from July 2007 to December 2008 constitute the study subjects. Their case notes were retrieved and data including operative complications analysed. The commonest type of surgery was extracapsular cataract extraction with intraocular lens implant. The follow up period was six months.

Results: There were 181 males and 189 females with a male to female ratio of 1:1. The age range was 4 to 95 years ( mean age 41.1 years). There was no intraoperative complication in 311 (84.0\%) eyes. The commonest intraoperative complication was posterior capsular rent in $31(8.4 \%)$ eyes. The commonest early post operative complication was striate keratopathy in 158 eyes. Endophthalmitis occurred in $2(0.6 \%)$ eyes with fair visual outcome. The commonest late postoperative complication, cystoid macular oedema (CMO) occurred in 9 eyes followed by posterior capsular opacification(PCO) in 6 eyes. The visual outcome was fair in 6 eyes with cystoid macula oedema and poor in 5 eyes with posterior capsular opacity. There was a significant association between the eyes with late post operative complications and the development of poor vision $p<0.0001$.

Conclusion: The commonest intraoperative complication was posterior capsular rent with or without vitreous loss while the commonest intraoperative complication was striate keratopathy. Visual outcome was not significantly affected by the early postoperative complication, but was significantly affected by late postoperative complication. Proper management of operative complications will help in reducing their adverse effects on the eye.

Key words: cataract surgery, operative, complications, visual outcome

\section{INTRODUCTION}

Vision loss from unoperated cataract represents an estimated $50 \%$ or more of the global burden of blindness ${ }^{1}$. The usual treatment is surgical cataract extraction with intraocular lens implant. The causes of po or visual outcome after surgery can be classified as pre existing eye disease, surgical or post operative complications, refractive errors and late post operative complications. ${ }^{2}$ In most population-based studies, inadequate refractive correction and surgical complications were the causes of poor visual outcome. ${ }^{2}$ Poor vision after surgery is caused by inadequate correction of post operative refractive error, failure to detect preexisting diseases or surgical complications ${ }^{2}$ It is estimated that about $25 \%$ of poor outcomes of cataract operations performed in developing countries annually are due to surgical complications. ${ }^{3}$

Proper management of operative complications will help in reducing the visual loss from these complications. Golgate and Kulkarni ${ }^{4}$ in a comparison of cataract surgery in a base hospital and in peripheral eye camps reported vitreous loss and posterior segment pathology to be the main causes of low post operative vision.

Various studies from Nigeria have reported complications from cataract extraction to include rupture of the posterior capsule, vitreous loss, striate keratopathy, posterior capsular opacities, uveitis, elevated intraocular pressure and others. ${ }^{5-10}$. Sanjay et $\mathrm{al}^{11}$ in a study on cataract surgeries in Nepal reported that $21 \%$ of the patients

*Correspondence: Dr Catherine U. Ukponmwan, Dept of Ophthalmology, School of Medicine, University of Benin, PMB 1111, Benin City, Nigeria • e-mail: kateukponmwan@yahoo.com 
developed PCO while Nwosu ${ }^{7}$ and Adepoju ${ }^{9}$ reported 7.3 $\%$ and $23 \%$, respectively.

The aim of this study is to investigate the complications of cataract extraction at the University of Benin Teaching Hospital, Benin City, determine their effect on visual outcome and to suggest ways to reduce the incidence and adverse effects of these complications.

\section{MATERIALS AND METHODS}

All consecutive patients who had cataract surgery in the Ophthalmology Department of University of Benin Teaching Hospital (UBTH) from July 2007 to December 2008 were included in this study. Patients excluded from the study were those below 4 years of age due to poorly assessed visual acuities, patients who had combined trabeculectomy and cataract extraction with IOL, eyes with no perception of light pre operatively and patients with incomplete records. These patients constitute the same subjects in our study of visual outcome of cataract surgery.

The patients were followed up for 6 months postoperatively. All patients' files were retrieved, recorded and analyzed. Three hundred and seventy eyes (370) of 358 patients were included in the study. Demographic data such as age, sex, occupation, tribe, associated systemic/ocular conditions, preoperative and post operative visual acuity, systemic and ocular examination findings, type of surgery done and the type of intraocular lens inserted were noted.

There is a standard protocol used in the department for the pre and postoperative management of all patients for cataract surgery. The patients included in this study were prepared using this protocol and patients who did not meet these criteria were excluded from the study.

The patients were admitted and prepared one day before surgery. General physical and ocular examinations were performed. The eye was dilated with tropicamide or cyclopentolate. Local anaesthesia (facial and retrobulbar) using $2 \%$ lignocaine or xylocaine with or without adrenaline and $0.5 \%$ bupivacaine was used for adults while general anaesthesia was used for children. All operations were performed with operating microscopes. No biometry was done because the equipment was not available. The intraocular lens power was calculated from the previous refraction of the patient in the affected eye if available or the other eye or the lens was selected from a standard stock available in the hospital.

Standard extra capsular cataract extraction (ECCE) with posterior or anterior chamber IOL (PCIOL/ACIOL) was mostly done. A fornix based conjunctival flap was used. A limbal incision was made superiorly. Viscoelastic material was used to maintain the anterior chamber depth and ringer's lactate was used as irrigating fluid. The IOL inserted was a single piece intraocular lens and the power was between +18.5 and +22.5 D. Anterior chamber IOL (AC IOL) was inserted in patients with preoperative subluxated or dislocated cataract or intraoperative rupture of the posterior capsule. Subconjunctival injection of ceftazidime $100 \mathrm{mg}$, gentamicin $20 \mathrm{mg}$ and dexamethasone $4 \mathrm{mg}$ was given at the end of the operation, ciprofloxacin or chloramphenicol, tropicamide and dexamethasone or bethamethasone eye drops were instilled at the end of surgery. Postoperative medication included topical antibiotics, steroid, mydriatic such as ciprofloxacin, chloramphenicol, bethamethasone, tropicamide, oral acetazolamide, analgesic and ascorbic acid.

Patients without complications after surgery were discharged the next day. Post-operative visual acuity was assessed using the Snellen's chart with or without pinhole $(\mathrm{PH})$ on $1^{\text {st }}$ day post operative $\left(1^{\text {st }} \mathrm{DPO}\right), 1$ week, 6 weeks, 3 months and 6 months. Post-operative refraction was done at 6 weeks. The visual acuity was classified according to World Health Organization's recommendation of: Good being 6/6$6 / 18$, borderline (fair) $<6 / 18-6 / 60$ and poor $<6 / 60^{8}$. In our study, IOP measurement was carried out pre- and postoperatively. Post-operative IOP recorded on the $1^{\text {st }}$ day, $1^{\text {st }}$ week, $6^{\text {th }}$ week, $3^{\text {rd }}$ month and $6^{\text {th }}$ month were used.

The complications were classified into intra-operative complications; early post-operative complications for complications occurring within 6 weeks of surgery; and late post-operative complications for problems occurring 6 weeks after surgery.

The data was then analyzed using EPI info 13. Frequencies, mean and chi square were calculated. $P$ value $\leq 0.05$ was taken as significant.

\section{RESULTS}

There were 358 patients included in the study, and the total number of eyes was 370 . There were 346 unilateral cases and 12 bilateral cases. Forty patients were lost to follow up at the end of 6 months. Children less than 4 years of age were excluded from the study.

There were 181 male and 189 female patients; the male to female ratio was approximately $1: 1$. The age range was 4 to 95years with a mean age of 41.1 years.

The mean preoperative intraocular pressure (IOP) was $13.3 \mathrm{mmHg}, 349$ (94.3\%) eyes had IOP within the normal range of $10-21 \mathrm{mmHg}$. $5(1.4 \%)$ eyes had IOP greater than $21 \mathrm{mmHg}$. 
Post-operatively, on the $1^{\text {st }}$ day following surgery, 18 $(4.8 \%)$ eyes had IOP greater than $21 \mathrm{mmHg}$. By the $6^{\text {th }}$ month after surgery, 297 (90\%) eyes of the remaining 330 eyes had IOP within normal range. Only $21(6.4 \%)$ eyes and $4(1.2 \%)$ eyes had IOP less than $10 \mathrm{mmHg}$ and greater than $21 \mathrm{mmHg}$ respectively. Also, the mean IOP progressively increased from $10.2 \mathrm{mmHg}$ on the $1^{\text {st }}$ post-operative day to $13.2 \mathrm{mmHg}$ on the $6^{\text {th }}$ post-operative month. The difference between the mean pre-operative IOP of $13.3 \mathrm{mmHg}$ and the mean IOP of $13.2 \mathrm{mmHg}$ at 6 months post- operatively was not statistically significant $p>0.05$.

Forty eyes (10.2\%) eyes were lost to follow up at the end of 6 months, consequently late post-operative complications were not recorded for these eyes.

Table 1 shows the intra-operative and post- operative complications, $311(84.0 \%)$ had no intra-operative complications. The commonest intra-operative complication was posterior capsular rent in $31(8.4 \%)$ eyes with associated vitreous loss in $25(6.8 \%)$ eyes.

Table 1. Intra-operative and early post-operative complications

\begin{tabular}{|c|c|c|}
\hline Complications & No. of eyes & $\%$ \\
\hline \multicolumn{3}{|l|}{ Intraocular Complications } \\
\hline Stripping of Descemet membrane & 18 & 4.3 \\
\hline Hyphema & 8 & 2.2 \\
\hline $\begin{array}{l}\text { Posterior capsular rent without } \\
\text { vitreous loss }\end{array}$ & 6 & 1.6 \\
\hline $\begin{array}{l}\text { Posterior capsular rent with } \\
\text { vitreous loss }\end{array}$ & 25 & 6.8 \\
\hline Zonular dehisence & 1 & 0.3 \\
\hline Retrobulbar haemorrhage & 1 & 0.3 \\
\hline No complication & 311 & 84 \\
\hline Total & 370 & 100 \\
\hline \multicolumn{3}{|l|}{ Early Post-operative Complications } \\
\hline Striate keratopathy & 158 & 42.7 \\
\hline Cortical remnants & 33 & 8.8 \\
\hline Shallow anterior chamber & 12 & 3.2 \\
\hline Post-operative uveitis & 11 & 3 \\
\hline Conjunctival discharge & 9 & 2.4 \\
\hline Iris prolapse & 7 & 1.9 \\
\hline Elevated IOP & 5 & 1.4 \\
\hline Pupillary capture & 2 & 0.6 \\
\hline Endophthalmitis & 2 & 0.6 \\
\hline No post op complications & 131 & 35.4 \\
\hline Total & 370 & 100 \\
\hline
\end{tabular}

The commonest early post-operative complication was striate keratopathy which occurred in 158 (42.7\%) eyes followed by cortical remnant in $33(8.8 \%)$ eyes, shallow anterior chamber in 12 (3.2\%) eyes and uveitis in 11 (3-0\%). Endophthalmitis and pupillary capture were seen in 2 eyes each. There was no early post- operative complications in 131 (35.4\%) eyes. The striate keratopathy resolved within a few days with proper management (topical steroids) and had no effect on the visual outcome.

There was no late post-operative complication in 299 $(90.6 \%)$ eyes. The commonest late post-operative complication was cystoid macular oedema (CMO) which occurred in $9(2.7 \%)$ eyes followed by posterior capsular opacification (PCO) and elevated IOP in 6 eyes (1.8\%) each. The visual outcome for 6 out of the 9 eyes with CMO was fair, 5 out 6 eyes that had PCO had poor visual outcome. Elevated IOP did not seem to have any immediate effect on the visual outcome. There was a significant association between eyes with late postoperative complication and poor visual outcome $<0.0001$.

The visual outcome was good in 218 (72.9\%) out of the 299 eyes without late post-operative complications and 222 $(67.3 \%)$ of 330 eyes at 6 post-operatively. There was a significant association between eyes without complications and good vision $\mathrm{p}<0.0001$.

\section{DISCUSSION}

The prevention of intra-operative and post-operative complications during and after cataract surgery and the proper management of these complications when they occur remain an important determinant of the visual outcome following cataract surgery. Surgical compli-cations can to some extent be prevented by good practice and good surgical technique. When complications occur proper management is crucial to reduce the possibility of poor outcome. $^{3}$

Pre-operatively, $94 \%$ of eyes had IOP within the normal range of $10-21 \mathrm{mmHg}$ with a mean IOP of $13.3 \mathrm{mmHg}$. Some of these patients were known glaucoma patients with IOP controlled on medications. The IOP was greater than $21 \mathrm{mmHg}$ in $1.4 \%$ of eyes. These eyes had complicated cataract and elevated IOP, and had a poor response to conventional IOP lowering drugs. Post-operatively, on the $1^{\text {st }}$ day, $40.8 \%$ of eyes had IOP less than $10 \mathrm{mmHg}$ and $4.8 \%$ of eyes had IOP greater than $21 \mathrm{mmHg}$ and were commenced on aggressive antiglaucoma therapy. This was better than the $9.3 \%$ of eyes on the $1^{\text {st }}$ day and $4.7 \%$ of eyes on the $5^{\text {th }}$ day 
post-operatively with an IOP greater than $21 \mathrm{mmHg}$ recorded by Adio et al. ${ }^{6}$ in their study in Port Harcourt, Nigeria.

There was a gradual reduction in the number of eyes in both categories $(<10 \mathrm{mmHg}$ and $>21 \mathrm{mmHg})$ so that by the $6^{\text {th }}$ post-operative month, $90 \%$ of 330 eyes had IOP between $10-21 \mathrm{mmHg}$. Only $1.2 \%$ of eyes had IOP above $21 \mathrm{mmHg}$ and they were known glaucoma patients with poor compliance with their medications. This was better than the $6 \%$ recorded by Olusanya et $\mathrm{al}^{12}$ in their study on visual recovery in children after cataract surgery.

The most common intra-operative complication was posterior capsular rent which was seen in $8.4 \%$ of eyes and vitreous loss which was seen $6.8 \%$ of these eyes. This was lower than that of $12 \%$ of vitreous loss by Olatunji et al, ${ }^{13}$ but higher than other findings from Nigeria of $6.3 \%$ by Adepoju, ${ }^{9}$ $4.9 \%$ by $\mathrm{Nwosu}^{7}$ and $4.7 \%$ by Adio. ${ }^{6}$ Chirambo $^{14}$ from Malawi reported that $3.4 \%$ of the patients in their study had posterior capsular rent. Posterior capsular rent and vitreous loss has also been found to be the commonest intra-operative complication by other authors from Nigeria., ${ }^{6,13,15}$

There was no intra-operative complication in $84 \%$ of eyes and this was comparable to Adio's report of $88.4 \%{ }^{6}$ The incidence of capsular rupture and vitreous loss is lower $(1-2 \%)$ in high income countries and is probably due to the use of phaco-emulsification and earlier intervention. ${ }^{3}$ In low and middle income countries the incidence is higher. ${ }^{16}$ This is also shown in our study and is probably due to the fact that cataract surgeries in developing countries are more complicated due to late presentation of the patients, couching and the use of traditional eye medications. Couching results in a subluxated or dislocated lens, uveitis, synechiae formation and more manipulation during surgery, thus increasing the risk of capsular rupture and vitreous loss. The use of traditional eye medication also results in uveitis, synechiae formation and a complicated cataract, thus increasing the risk of capsular rupture and vitreous loss during surgery. Proper management of these cases with anterior vitrectomy and insertion of an intraocular lens will lead to a better visual outcome.

The commonest early post-operative complication, striate keratopathy which was seen in $42.7 \%$ of eyes, is lower than that of $53.1 \%$ reported by Adio, ${ }^{6}$ but higher than that of $25.4 \%$ and $9.8 \%$ reported by Adepoju ${ }^{9}$ and Bekibele, ${ }^{8}$ respectively. The other post-operative complications such as uveitis, cortical remnant, pupillary capture have also been reported by other studies on complications of cataract surgery..$^{5-9}$ Uveitis is a common complication of cataract extraction which occurred in $3.0 \%$ of eyes in this study and is lower than that of $48.8 \%$ of recurrent uveitis reported by $\mathrm{Nwosu}^{7}$ and $16.4 \%$ by Bekibele. ${ }^{7}$

Eruchalu $^{17}$ had complications in 119 eyes (3.6\%) with striate keratitis accounting for $30.6 \%$ of eyes and hyphaema in $10.6 \%$. Hyphaema was not seen as a post operative complication in this study and this may be due to proper cauterization of bleeding vessels and adequate irrigation of blood during surgery.

Endophthalmitis which is a vision threatening and dreaded complication of cataract surgery was seen in two patients in this study. The visual outcome was fair in both patients because of early recognition and intensive management. The reported incidence of endophthalmitis in Nigeria varies from $4.9 \%$ by Bekibele ${ }^{8}$ to $8.7 \%$ by Akinsola. ${ }^{10}$ There was no endophthalmitis in most of the studies from Nigeria. ${ }^{5,7,9}$ The incidence has been reported to be between $0.13 \%$ and $0.7 \% .^{18}$

Adequate measures should be taken before, during and after surgery to prevent the development of endophthalmitis. Proper preparation of the patient including reducing risk factors that increase the presence of bacteria on ocular surface such as blepharitis, conjunctivitis, canaliculitis, lacrimal duct obstruction, contact lens wear, and ocular prosthesis in the other eye, use of $5 \%$ povidone iodine eye drops, use of aseptic technique, injection of intracameral cefuroxime post- operatively will help to reduce the occurrence of endophthalmitis. ${ }^{19}$

Effective management of complications such as capsular rupture is also important. Early recognition and proper management of endophthalmitis with intravitreal vancomycin and either ceftazidime or amikacin is important to achieve good or fair visual outcome as in this study where both patients had fair visual outcome. Diabetic patients should be properly controlled before surgery. One of the patients with endophthalmitis in this study was diabetic.

Early postoperative complications were not recorded in $35 \%$ of eyes and were higher than that of $25.6 \%$ reported by Adio. ${ }^{6}$ These early complications did not affect the final visual outcome significantly as almost all the patients except two (who developed bullous keratopathy) had clear cornea by the end of the first postoperative week after the administration of subconjunctival and/or topical steroids.

The commonest late postoperative complication was cystoid macula oedema (CMO) which occurred in $2.7 \%$ (9) of eyes. Six $(1.8 \%)$ of these eyes had fair $(6 / 18-6 / 60)$ visual outcome. CMO was not recorded in most other studies. PCO and elevated IOP were seen in $1.8 \%$ (6) of eyes each. 
Table 2. Late post-operative complications and final visual outcome

\begin{tabular}{|c|c|c|c|c|c|c|}
\hline \multirow[t]{2}{*}{ Complications } & \multirow{2}{*}{ No of eyes } & \multirow{2}{*}{$\%$} & \multicolumn{4}{|c|}{ Final visual outcome } \\
\hline & & & Good & Fair & Poor & Nil Rec VA \\
\hline Cystoid macular oedema & 9 & 2.7 & - & 6 & 3 & - \\
\hline Elevated IOP & 6 & 1.8 & 3 & 2 & 1 & - \\
\hline Posterior capsular opacification & 6 & 1.8 & - & 1 & 5 & - \\
\hline Pupillary membrane & 3 & 0.9 & 1 & 2 & - & - \\
\hline Ocular hypotony & 2 & 0.6 & - & - & 2 & - \\
\hline Bullous keratopathy & 2 & 0.6 & - & - & 2 & - \\
\hline Phthisis bulbi & 1 & 0.3 & - & - & 1 & - \\
\hline Lost IOL & 1 & 0.3 & - & - & 1 & - \\
\hline Retinal detachment & 1 & 0.3 & - & - & 1 & - \\
\hline NIL & 299 & 90.6 & 218 & 49 & 16 & 16 \\
\hline TOTAL & 330 & 100 & 222 & 60 & 32 & 16 \\
\hline Lost to follow up & 40 & 10.8 & & & & \\
\hline
\end{tabular}

Olusanya ${ }^{12}$ in his study in children after cataract surgery recorded $41.1 \%$ of PCO and $6 \%$ of elevated IOP. Nwosu recorded $7.3 \%$ while $\operatorname{Singh}^{11}$ recorded $0.5 \%$. Visual acuity can be improved in eyes with posterior capsular opacities by performing an $\mathrm{Nd}$ Yag laser capsulotomy or a surgical capsulotomy using a $25 \mathrm{G}$ capsulotomy needle ${ }^{20}$

Late post-operative complications were not recorded in $90.6 \%$ (299) of eyes. Out of these, 218 eyes had good visual outcome. This represented $72.9 \%$ of eyes without late postoperative complications and $66.1 \%$ of the total eyes at 6 months post operatively. This further underscores the fact that late post-operative complications affect the final visual outcome more adversely than early post-operative complications.

Good surgical skills and proper management of intraoperative complications are necessary for achieving a good visual outcome following cataract surgery. Post-operative management is as important as the surgery itself since prompt and proper management of early post-operative complications will prevent late post-operative complications and poor visual outcome. Regular monitoring of cataract surgical outcomes is important as it is associated with a reduction in the incidence of complications. ${ }^{21}$ Proper management of complications should be incorporated into training programmes as this will improve the visual outcome after cataract surgery.

\section{CONCLUSION}

The commonest intraoperative complication in this study was posterior capsular rent with or without vitreous loss while the commonest early postoperative complication was striate keratopathy. Visual outcome in this study was not significantly affected by the early post-operative complications, but was significantly affected by late postoperative complications, it is, therefore, important to manage these complications properly to prevent visual loss.

\section{REFERENCES}

1 Parajasegaram R. Importance of monitoring cataract surgical outcomes. Journal of Community Eye Health 2002; 15: 49-50.

2 Dandona L, Limburg H. What do we mean by cataract outcomes? Comm Eye Health Journal 2000;13: (35), 35-36.

3 Yorston D. Cataract complications. Comm. Eye Health Journal 2008; 21:(65), 1-3.

4 Gogate P, Kulkarni AN. Comparison of cataract surgery in a base hospital and in peripheral eye camps. Community Eye Health Journal 2002; 15: (42), 26-27.

5 Umeh RE, Onwasigwe EN. Ozoh GA, Onwasigwe E N. Okoye OI., Umeh OC, Cataract intervention surgery: A community approach. Nig J. Ophthalm 2000; 8:17-20.

6 Adio AO, Awoyesuku E. Early experience with intraocular lens implantation surgery in University of Port Harcourt Teaching Hospital, Port Harcourt, Nigeria. Port Harcourt Medical Journal 2007; 1:178-85.

7 Nwosu SNN, Onyekwe CO. Intraocular lens implantation surgery in Onitsha, Nigeria. Nig J Ophthalmol 2002;1: 5-9.

8 Bekibele CO. Evaluation of the outcome of ECCE surgery withPC IOL at Ago-Iwoye, Ogun State, Nigeria. Nig J Ophthalmol 2001; 9: 32-36.

9 Adepoju FG, Owoeye JFA, Ademola-Popoola DS. Assessments of one year follow up of patients with ECCE_PCIOL surgery at Ilorin Teaching Hospital, Kwara 
State, Nigeria. Nig J Ophthalmol 2004; 12: 65-67.

10 Akinsola FB, Hassan AA, Majekodunmi AA, AdefuleOsitelu AO, Onakoya AO, Aribaba OT. Post-operative complications of cataract surgery seen over a 5 year period (Jan 1998-Dec 2002). Nig Qt J Hosp Med 2004; 14: 56-59.

11 Singh SK, Dahal T, Sharma D. Early results of cataract surgeries in Mechi Eye Centre in Nepal. Comm Eye Health J 2002; 15 (42): 28-29.

12 Olusanya BA, Baiyeroju AM, Fajola AO. Visual recovery after cataract surgery in children. Nig J Ophthalmol 2006; 14 (2): 46-51.

13 Chirambo MC . Country-wide monitoring of cataract surgical outcomes. Community Eye Health Journal 2002; 15: 58-59.

14 Olatunji FO, Kirupananthan S. Intracapsular cataract extraction with anterior chamber intraocular lens implantation in a developing country. Nig J Ophthalmol 2006; 14: 13-17.

15 Mpyet C. Extracapsular cataract extraction with intraocular lens implantation in leprosy and non leprosy patients: Visual outcome and complications. Nig J Ophthalmol. 2006; 14:9-12.

16 Kothari M, Thomas R, Parikh R, Braganza A, Kuriakose T, Muliyi J. The incidence of vitreous loss and visual outcome in patients undergoing cataract surgery in a teaching hospital. Indian J Ophthalmol 2003; 51:45-52.

17 Eruchalu UV. Minimizing the complications of cataract surgery. Nig J Ophthalmol 1993; 2(1): 6-11.

18 Marmalis N, Kearsley L, Brinton E. Postoperative endophthalmitis. Curr Opin Ophthalmol 2002; 13: 14-18.

19 Niyadurupola N, Astbury N. Endophthalmitis.: Controlling infection before and after cataract surgery. Comm Eye Health J 2008; 21: (65) 9-10.

20 Waziri Erameh J M, Omoti AE, Pedro-Egbe CN. Non laser management of post-extraction opacification of the posterior capsule. Nig J Surgical Sciences 2007; 17: 101-104.

21. Limburg H, Forster A, Gilbert C, Johnson GJ, Kyndt M, Myatt M. Routine monitoring of the outcome of cataract surgery. Part 2: Results from eight study centres. $\mathrm{Br} J$ Ophthalmol 2005; 89 (1): 50-52. 